\title{
LA RESPONSABILIDAD CIVIL EXTRACONTRACTUAL DERIVADA DE ACCIDENTES DE CIRCULACIÓN. SAP BARCELONA 19 JUNIO 2020
}

\author{
THE CIVIL NON-CONTRACTUAL LIABILITY ARISING \\ FROM ROAD TRAFFIC ACCIDENTS. \\ JUDGEMENT OF THE AP BARCELONA 19 JUNE 2020
}

\author{
Celia M. CaAmiña Domínguez \\ Profesora titular de Derecho internacional privado \\ Universidad Carlos III de Madrid \\ ORCID ID: 0000-0003-1790-9467
}

Recibido: 03.12.2020 / Aceptado: 21.12.2020

DOI: https://doi.org/10.20318/cdt.2021.5985

\begin{abstract}
Resumen: El presente trabajo trata sobre la responsabilidad civil extracontractual derivada de un accidente de circulación ocurrido Portugal. Será analizada la competencia judicial internacional de los tribunales españoles conforme al Reglamento 1215/2012 y la aplicabilidad del Convenio de La Haya de 1971.

Palabras clave: accidente de circulación, perjudicado, asegurador, Reglamento 1215/2012, Convenio de La Haya de 1971.

Abstract: This paper deals with the civil non-contractual liability arising from a road traffic accident in Portugal. The jurisdiction of the Spanish courts by virtue of Regulation (EU) 1215/2012 and the applicability of the 1971 Hague Convention will be analysed.
\end{abstract}

Keywords: road traffic accident, injured party, insurer, Regulation (EU) 1215/2012, 1971 Hague Convention.

Sumario: I. Introducción. II. Hechos del caso. III. Competencia judicial internacional. A) Norma aplicable. B) Foros para el ejercicio de la acción directa. IV. Ley aplicable. A) Norma aplicable. B) La Ley del país del accidente. V. Prueba del Derecho extranjero. VI. Conclusiones.

\section{Introducción}

1. En el presente trabajo se analiza la SAP Barcelona 19 junio 2020, relativa a la responsabilidad civil extracontractual derivada de un accidente de circulación que tuvo lugar en una carretera de Portugal en julio de $2016^{1}$.

2. Serán objeto de análisis una serie de cuestiones de la Sentencia, relativas a la competencia judicial internacional, la Ley aplicable y la prueba del Derecho extranjero.

${ }^{1}$ SAP $\left(\right.$ Sección 1 ${ }^{\text {a) }}$ Barcelona 19 junio 2020, Roj: SAP B 5205/2020, ECLI: ES:APB:2020:5205. 
Así, serán tratados los siguientes aspectos:

a) La norma sobre competencia judicial internacional y el foro que permite conocer de este asunto a los tribunales españoles. Se determinará si es aplicable un foro del Reglamento (CE) núm. 44/2001 del Consejo, de 22 de diciembre de 2000, relativo a la competencia judicial, el reconocimiento y la ejecución de resoluciones judiciales en materia civil y mercanti ${ }^{2}$, tal y como se sostuvo en la resolución de primera instancia; o el Reglamento (CE) núm. 1215/2012 del Parlamento Europeo y del Consejo, de 12 de diciembre de 2012, relativo a la competencia judicial, el reconocimiento y la ejecución de resoluciones judiciales en materia civil y mercantil ${ }^{3}$.

b) La norma que determina la Ley aplicable a la responsabilidad civil extracontractual y cuál es dicha Ley. Como se verá, en la Sentencia se reflexiona sobre la relación existente entre el Convenio sobre la Ley aplicable en materia de accidentes de circulación por carretera, hecho en La Haya el 4 de mayo de 1971 y el Reglamento (CE) núm. 864/2007 del Parlamento Europeo y del Consejo, de 11 de julio de 2007, relativo a la ley aplicable a las obligaciones extracontractuales ("Roma II")4.

c) La prueba del Derecho extranjero y, en concreto, la relevancia del art. 33.3 de la Ley 29/2015, de 30 julio, de Cooperación Jurídica Internacional en Materia Civil ${ }^{5}$.

\section{Hechos del caso}

3. El 26 de julio de 2016 tuvo lugar un accidente de circulación en una carretera de Portugal ${ }^{6}$. En dicho accidente, resultaron implicados dos vehículos: un camión de matrícula española y un camión articulado de matrícula portuguesa? ${ }^{7}$.

4. El propietario del camión de matrícula española demandó a la representante española de la aseguradora portuguesa del camión articulado ${ }^{8}$. El demandante alegaba que el accidente había sido provocado por el adelantamiento del camión de matrícula portuguesa cuando el camión de matrícula española había señalizado ya una maniobra de giro9. Así, ante los tribunales españoles, el demandante solicitó una indemnización de 12.100 euros, correspondiente al coste de reparación del camión que había tenido que abonar ${ }^{10}$.

5. La representante española de la aseguradora portuguesa se opuso alegando que la causa del accidente había sido la incorrecta maniobra de giro y que el atestado de la policía portuguesa no respaldaba las alegaciones del demandante ${ }^{11}$. Así, la demandada consideraba que era la aseguradora española del camión de matrícula española la que debía indemnizar por los daños que había sufrido el camión articulado de matrícula portuguesa ${ }^{12}$.

\footnotetext{
${ }^{2}$ DOCE núm. L 12, de 16 enero 2001, ELI: http://data.europa.eu/eli/reg/2001/44/oj.

${ }^{3}$ DOUE núm. L 351, de 20 diciembre 2012, ELI: http://data.europa.eu/eli/reg/2012/1215/oj .

${ }^{4}$ Respectivamente, Instrumento de ratificación de 4 septiembre 1987, BOE núm. 264, de 4 noviembre 1987; rect. $B O E$ núm. 307, de 24 diciembre 1987, https://www.boe.es/buscar/doc.php?id=BOE-A-1987-24741 y DOUE núm. L 263, de 7 octubre 2009, ELI: http://data.europa.eu/eli/reg/2007/864/oj .

${ }^{5}$ BOE núm. 182, de 31 julio 2015, https://www.boe.es/eli/es/1/2015/07/30/29 .

${ }^{6}$ SAP (Sección 1 ${ }^{\text {a }}$ ) Barcelona 19 junio 2020, Roj: SAP B 5205/2020, ECLI: ES:APB:2020:5205, Fundamento de Derecho Primero, punto I.

7 Ídem.

8 Ídem.

9 Ídem.

${ }^{10}$ Ídem.

${ }^{11}$ Ibidem, Fundamento de Derecho Primero, punto II.

12 Ídem.
} 


\section{Competencia judicial internacional}

\section{A) Norma aplicable}

6. Mientras que en la resolución de primera instancia se aplicó el Reglamento (CE) núm. 44/2001 del Consejo, de 22 de diciembre de 2000, relativo a la competencia judicial, el reconocimiento y la ejecución de resoluciones judiciales en materia civil y mercantil (en adelante, Reglamento 44/2001); la Audiencia Provincial determina que la norma aplicable a tal extremo es el Reglamento (CE) núm. 1215/2012 del Parlamento Europeo y del Consejo, de 12 de diciembre de 2012, relativo a la competencia judicial, el reconocimiento y la ejecución de resoluciones judiciales en materia civil y mercantil (en adelante, Reglamento 1215/2012).

7. El Reglamento 44/2001 y el Reglamento $1215 / 2012$ resultan ambos aplicables a materia civil y mercantil (art. 1) -encontrándose incluida, por lo tanto, la responsabilidad civil extracontractual-; por los tribunales de los Estados miembros de la Unión Europea (respectivamente, art. 76 y art. 81); y, con carácter general, cuando el domicilio del demandado se encuentra en un Estado miembro (respectivamente, art. 2 y art. 4).

Existe una importante diferencia en lo que respecta al ámbito temporal, dado que el Reglamento 44/2001 era aplicable a las demandas interpuestas a partir del 1 de marzo de 2002 (art. 66.1 y art. 76); mientras que el Reglamento 1215/2012 sustituye al anterior en caso de demandas interpuestas a partir del 10 de enero de 2015 (art. 66.1, art. 80 y art. 81).

8. Por lo tanto, tal como indica la Audiencia Provincial, la norma aplicable para determinar la competencia judicial internacional es el Reglamento 1215/2012, dado que se interpuso la demanda después del 10 de enero de $2015^{13}$.

\section{B) Foros para el ejercicio de la acción directa}

9. Se señala que en primera instancia se demandó a la representante en España de la aseguradora portuguesa, tras la respuesta negativa a una reclamación extrajudicial, y que la demandada admitió que los tribunales españoles resultaban competentes en virtud de la Directiva 2000/26 del Parlamento Europeo y del Consejo de 16 de mayo de 2000, relativa a la aproximación de las legislaciones de los Estados miembros sobre el seguro de responsabilidad civil derivada de la circulación de vehículos automóviles y por la que se modifican las Directivas 73/239/CEE y 88/357/CEE del Consejo (Cuarta Directiva sobre el seguro de vehículos automóviles) y del Reglamento 44/2001 ${ }^{14}$.

En la SAP se indica que conforme al “...indicado Reglamento $n^{\circ}$ 1215/2012 (art. 4.1), las personas domiciliadas en un Estado miembro estarán sometidas, sea cual sea su nacionalidad, a los órganos jurisdiccionales de dicho Estado. Por tanto, al resultar acreditado que la entidad demandada tiene domicilio en España, es clara la competencia de los tribunales españoles. La parte demandada no ha hecho cuestión de esta materia, de modo que, en todo caso, se daría el supuesto previsto en el artículo 26.1 del Reglamento 1215/2012 dado que el demandado ha comparecido en las actuaciones sin discutir la indicada competencia" 15 .

10. Habiendo ya sido aclarado que la norma aplicable es el Reglamento $1215 / 2012$, cabe referirse a continuación a la circunstancia de que se ha demandado al representante español para la tramitación y liquidación de siniestros de la aseguradora portuguesa.

\footnotetext{
${ }^{13}$ Ibidem, Fundamento de Derecho Segundo, punto II.

${ }^{14}$ Ibidem, Fundamento de Derecho Primero, puntos I y II. Sobre la Directiva 2000/26, vid. DOCE núm. L 181, de 20 julio 2000, ELI: http://data.europa.eu/eli/dir/2000/26/oj .

${ }^{15}$ SAP (Sección 1ª) Barcelona 19 junio 2020, Roj: SAP B 5205/2020, ECLI: ES:APB:2020:5205, Fundamento de Derecho Segundo, punto II.
} 
En el caso, se hace referencia a la Directiva 2000/26. Tanto la Directiva 2000/26 como la Directiva 2009/103/CE del Parlamento Europeo y del Consejo, de 16 de septiembre de 2009, relativa al seguro de la responsabilidad civil que resulta de la circulación de vehículos automóviles, así como al control de la obligación de asegurar esta responsabilidad ${ }^{16}$-que derogó la Directiva 2000/26-, establecen que la designación del representante para la tramitación y liquidación de siniestros no es un establecimiento a los efectos del Reglamento 44/2001 (art. 4.8 Directiva 2000/26 y art. 21.6 Directiva 2009/103) y, por lo tanto, tampoco lo es en el ámbito del Reglamento 1215/2012 ${ }^{17}$.

11. Ello nos hace plantearnos, entonces, la posible falta de legitimación pasiva del representante para la tramitación y liquidación de siniestros. Sobre esta cuestión se pronunció el TJUE en su Sentencia de 15 diciembre 2016, relativa a un accidente de circulación que tuvo lugar en España y con motivo del que se interpuso en Portugal una demanda contra el representante en Portugal de una aseguradora española. El TJUE determinó que "el artículo 4 de la Directiva 2000/26 debe interpretarse en el sentido de que no exige que los Estados miembros establezcan que ante los órganos jurisdiccionales nacionales que conozcan de acciones de indemnización ejercitadas por perjudicados (...) puedan ser demandados, en lugar de serlo las entidades aseguradoras a las que representan, los representantes mismos encargados, en virtud del propio artículo 4 de la Directiva, de la tramitación y liquidación de siniestros"18.

Al respecto, el Considerando trigésimo octavo de la Directiva 2009/103 determina que "La acción del representante para la tramitación y liquidación de siniestros no es suficiente para atribuir la competencia a los órganos jurisdiccionales del Estado miembro de residencia del perjudicado si ello no está previsto por normas de Derecho internacional privado sobre atribución de competencias jurisdiccionales". Por ello, para saber dónde puede el perjudicado demandar al asegurador del responsable -en ejercicio de la acción directa-, ha de acudirse a las normas de Derecho internacional privado y, como hemos indicado, dicha norma es el Reglamento 1215/2012.

12. En el caso, entendemos que el demandante desea ejercitar una acción directa ante los tribunales españoles contra el asegurador del sujeto al que considera responsable. El Reglamento 1215/2012 dedica a la competencia judicial internacional en materia de seguros la Sección 3 del Capítulo II, con la excepción del foro de la sumisión tácita, que se encuentra previsto en el art. $26^{19}$. En la Sección 3 del Capítulo II del Reglamento 1215/2012, se contempla el foro de sumisión expresa (art. 15) y, en defecto de la misma, una serie de foros que permiten al tomador, asegurado o beneficiario interponer una demanda contra el asegurador.

13. Cuando el demandante es el perjudicado, procede referirse al art. 13.2 del Reglamento 1215/2012, que establece que "Los artículos 10, 11 y 12 serán aplicables en los casos de acción directa entablada por la persona perjudicada contra el asegurador cuando la acción directa sea posible".

El art. 11.1.a) del Reglamento 1215/2012 determina que cabe demandar al asegurador ante los tribunales del Estado miembro de su domicilio. Como la aseguradora se encuentra domiciliada en Portugal, mediante este foro no lograría el demandante su objetivo de litigar ante los tribunales españoles.

\footnotetext{
${ }^{16}$ DOUE núm. L 263, de 7 octubre 2009, ELI: http://data.europa.eu/eli/dir/2009/103/oj .

${ }^{17}$ Vid. H. Heiss, “Article 13”, en U. Magnus / P. Mankowski (eds.), Brussels Ibis Regulation, Köln, Otto Schmidt, 2016, p. 425; F. F. Garau Sobrino, "El TJCE nuevo legislador comunitario (o cómo crear por vía de hecho un nuevo foro para las víctimas de los accidentes de circulación)", AEDIPR, t. VII, 2007, p. 649.

${ }^{18}$ STJUE 15 diciembre 2016, asunto C-558/15, Alberto José Vieira de Azevedo y otros contra CED Portugal Unipessoal, Lda, e Instituto de Seguros de Portugal - Fundo de Garantia Automóvel, ECLI:EU:C:2016:957, apartado 39. Vid. también la SAP Barcelona 13 junio 2018, Roj: SAP B 6940/2018, ECLI: ES:APB:2018:6940, en la que se apreció falta de legitimación pasiva del representante en España de una aseguradora francesa: “...se concluye que la ley española no establece una legitimación pasiva de los RTLS que permita su condena a abonar la responsabilidad de la aseguradora".

${ }^{19}$ Vid. STJUE 20 mayo 2010, Michal Bilas, asunto C-111/09, ECLI:EU:C:2010:290, en especial, apartados 24, 25 y 30. Entre otros, vid. A. L. Calvo Caravaca / J. Carrascosa González, "Notas breves sobre la Sentencia del TJUE (Sala Cuarta) de 20 mayo 2010 (BILAS: asunto C-111/09): la sumisión tácita en los litigios internacionales de seguro, consumo y trabajo", $C D T$, vol. 2, núm. 2, octubre 2010, pp. 236-241.
} 
Continuando con la remisión que hace el art. 13.2 del Reglamento 1215/2012 a los arts. 10, 11 y 12, cabe destacar que el art. 11.1.b) contempla el foro del lugar del domicilio de demandante. En virtud del pronunciamiento del TJCE en el caso Odenbreit, los perjudicados que se encuentran domiciliados en un Estado miembro pueden ejercitar una acción directa -siempre que la Ley aplicable la permita- ante los tribunales del lugar de su propio domicilio contra el asegurador del responsable que se encuentra domiciliado en un Estado miembro ${ }^{20}$.

14. Por ello, el demandante -perjudicado domiciliado en España-, podría demandar a la aseguradora portuguesa ante los tribunales españoles y, específicamente, ante los del lugar del concreto domicilio del demandante, al contemplar el art. 11.1.b) un foro especial, que determina la competencia judicial internacional y territorial ${ }^{21}$. Con ello, el perjudicado lograría por esta vía el objetivo de litigar ante los tribunales del lugar de su propio domicilio, sin tener que acudir a los tribunales portugueses (que son los tribunales del Estado miembro del domicilio del asegurador).

\section{Ley aplicable}

\section{A) Norma aplicable}

15. Tanto el demandante como el demandado consideran que la norma que ha de determinar la Ley aplicable es el Convenio sobre la Ley aplicable en materia de accidentes de circulación por carretera, hecho en La Haya el 4 de mayo de 1971 (en adelante, Convenio de La Haya de 1971), al entender que prevalece sobre el Reglamento (CE) núm. 864/2007 del Parlamento Europeo y del Consejo, de 11 de julio de 2007, relativo a la ley aplicable a las obligaciones extracontractuales ("Roma II"). Sin embargo, la Audiencia Provincial entiende que es aplicable el Reglamento Roma II, dado que "...un Reglamento de la UE siempre prevalecerá sobre un Convenio”, “...El principio de especialidad (...) no puede ser aplicado a la presente situación puesto que una Convención, por muy específica y particular que sea, nunca puede derogar o contradecir un Reglamento (...). Además, en cualquier caso, el Convenio de la Haya de 1971 tampoco resultaría de aplicación porque no ha sido ratificado por Portugal"22.

16. Con respecto al ámbito de aplicación del Convenio de la Haya de 1971, cabe recordar que ${ }^{23}$ : a) determina la Ley aplicable a la responsabilidad civil extracontractual resultante de los accidentes de circulación por carretera (art. 1); b) se encuentra en vigor para España desde el 21 de noviembre de 1987; c) es un Convenio erga omnes, de tal forma que no resultan relevantes datos como el lugar en el que se ha producido el accidente, las circunstancias personales de las partes (ej. nacionalidad, domicilio, residencia habitual) ni las circunstancias del vehículo.

\footnotetext{
${ }^{20}$ STJCE 13 diciembre 2007, FBTO Schadeverzekeringen NV contra Jack Odenbreit, asunto C-463/06, ECLI:EU:C:2007:792, apartados 25, 26 y 31 . Al respecto, vid., entre otros, V. FuENTES CAMACHO, "Los problemas de jurisdicción y ley en los accidentes de circulación transfronterizos", $R$ C. Revista de responsabilidad civil, circulación y seguro, año 46, núm. 2, febrero 2010, p. 16; F. F. Garau Sobrino, "El TJCE nuevo legislador comunitario (o cómo crear por vía de hecho un nuevo foro para las víctimas de los accidentes de circulación)", AEDIPR, t. VII, 2007, pp. 643-659; el comentario de la mencionada Sentencia de E. PATAUT, $R C D I P$, vol. 98, 2009, pp. 366-373; A. ORTEGA GIMÉNEZ, “3 x 1 = Competencia judicial internacional, determinación de la Ley aplicable y prueba del derecho extranjero en materia de accidentes de circulación por carretera (A propósito de la Sentencia de la Audiencia Provincial de Barcelona de 19 de junio de 2020)", Diario La Ley, núm. 9724, 27 octubre 2020, p. 6; L. F. REGLERO CAMPOS, "Competencia judicial internacional en materia de daños extracontractuales y de acción directa contra el asegurador de la responsabilidad civil (Notas a la sentencia del TSJCE de 13 de diciembre de 2007)", Diario La Ley, núm. 6894,29 febrero 2008, pp. 1817-1820. Cabe tener presente que el art. 18 de la Directiva 2009/103 establece que los Estados miembros han de garantizar el derecho de los perjudicados a tal acción directa.

${ }^{21}$ Vid., entre otros, H. Heiss, “Article 11", en U. Magnus / P. Mankowski (eds.), Brussels Ibis Regulation, Köln, Otto Schmidt, 2016, p. 415.

${ }^{22}$ SAP (Sección $1^{\text {a }}$ ) Barcelona 19 junio 2020, Roj: SAP B 5205/2020, ECLI: ES:APB:2020:5205, Fundamento de Derecho Tercero, punto I.

${ }^{23}$ A. L. Calvo Caravaca / J. Carrascosa González, "Obligaciones extracontractuales”, en A. L. Calvo Caravaca / J. CaRRASCOSA GonZÁlez (dirs.), Tratado de Derecho internacional privado, t. III, Valencia, Tirant lo blanch, 2020, pp. 1080-1081.
} 
Por su parte, el Reglamento Roma $\mathrm{II}^{24}$ : a) rige la Ley aplicable a las obligaciones extracontractuales en materia civil y mercantil -estando incluida la responsabilidad civil extracontractual derivada de accidentes de circulación por carretera- (art. 1); b) se aplica a los hechos generadores del daño producidos a partir del 11 de enero de 2009; c) vincula a todos los Estados miembros de la Unión Europea salvo Dinamarca; d) es un Reglamento erga omnes.

17. Cuando se trata de un caso en el que resultan competentes los tribunales españoles, al ser España un Estado parte del Convenio de La Haya de 1971 y también al resultar vinculado por el Reglamento Roma II, resulta preciso concretar cuál de las dos normas ha de prevalecer.

Al respecto, procede referirse al art. 28 del Reglamento Roma II y al art. 15 del Convenio de La Haya de 1971. El art. 28 del Reglamento Roma II establece que: "1. El presente Reglamento no afectará a la aplicación de los convenios internacionales en que sean parte uno o más Estados miembros en el momento de la adopción del presente Reglamento y que regulen los conflictos de leyes en materia de obligaciones extracontractuales. 2. No obstante, por lo que respecta a las relaciones entre Estados miembros, el presente Reglamento, en la medida en que afecte a las materias reguladas por el mismo, primará frente a los convenios celebrados exclusivamente entre dos o más Estados miembros". El art. 15 del Convenio de La Haya de 1971 determina que el Convenio no afecta a otros Convenios presentes o futuros "que, en materias específicas, contengan disposiciones relativas a la responsabilidad civil extracontractual derivada de accidentes de circulación por carretera" 25 .

18. Teniendo en cuenta que: a) el Convenio de La Haya de 1971 regula una materia también incluida en el ámbito de aplicación del Reglamento Roma II; b) el Convenio de La Haya de 1971 es un convenio internacional de fecha anterior al Reglamento Roma II; c) el Convenio de La Haya de 1971 es un convenio internacional del que son parte tanto algunos Estados miembros como terceros Estados -es decir, no es un convenio celebrado exclusivamente entre Estados miembros-; y d) el Reglamento Roma II es una norma de carácter general, no específico; entonces, para los Estados miembros que son parte en el Convenio de La Haya de 1971 -como España-, el Convenio es el instrumento que ha de determinar la Ley aplicable ${ }^{26}$.

19. La norma aplicable sería diferente en caso de que se hubiera demandado al asegurador ante los tribunales portugueses ya que, en tal supuesto, al no haber ratificado Portugal el Convenio de La Haya de 1971, sí que sería aplicable el Reglamento Roma II por los tribunales portugueses ${ }^{27}$.

\section{B) La Ley de país del accidente}

20. La SAP determina aplicable la Ley portuguesa, en virtud del art. 4.1 del Reglamento Roma II. Como se ha expuesto, procede en realidad aplicar el Convenio de La Haya de 1971. Así, teniendo en

\footnotetext{
${ }^{24}$ Ibidem, pp. 1005-1010.

${ }^{25}$ J. von Hein, “Article 4 and Traffic Accidents”, en J. AheRn / W. Binchy (eds.), The Rome II Regulation on the Law Applicable to Non-Contractual Obligations. A New International Litigation Regime, Leiden-Boston, 2009, pp. 157-158.

${ }^{26}$ Ídem y, entre otros, A. L. Calvo Caravaca / J. Carrascosa González, Las obligaciones extracontractuales en Derecho internacional privado. El Reglamento "Roma II", Granada, Comares, 2008, pp. 171-172; A. Dickinson, The Rome II Regulation. The Law Applicable to Non-Contractual Obligations, Oxford University Press, 2008, p. 359; H. Heiss, "Insurance Contracts in Rome I: Another Recent Failure of the European Legislature", Yearbook of Private International Law, vol. 10, 2008, p. 264; H. Heiss, “Article 13”, en U. Magnus / P. Mankowski (eds.), Brussels Ibis Regulation, Köln, Otto Schmidt, 2016, p. 423; P. A. DE Miguel Asensio, "El régimen comunitario relativo a la ley aplicable a las obligaciones extracontractuales", Revista Española de Seguros, núm. 140, 2009, p. 706; A. Ortega Giménez, “Aplicación del Derecho extranjero por los tribunales españoles para conocer de un supuesto de responsabilidad civil extracontractual por un accidente de circulación por carretera ocurrido en Portugal. Comentario a la SAP de Pontevedra, Sección 6a, 293/2014 de 16 de mayo, rec. 959/2012”, Revista Boliviana de Derecho, núm. 21, 2016, p. 319.

${ }^{27}$ Sobre los Estados que han ratificado el Convenio de La Haya de 1971, vid. https://www.hcch.net/es/instruments/conventions/status-table/?cid=81 (fecha de consulta: 26 noviembre 2020).
} 
cuenta que en el accidente estuvieron implicados dos vehículos matriculados uno en España y otro en Portugal, y que no resultaron implicadas personas que se encontrasen fuera de los vehículos, resulta de aplicación el art. 3 del Convenio de La Haya de $1971^{28}$. Conforme a dicho precepto, la Ley aplicable es la Ley interna del Estado en cuyo territorio tuvo lugar el accidente, es decir, la Ley portuguesa.

21. La Ley portuguesa es la que determina, por un lado, que el demandante puede ejercitar la acción directa contra el asegurador del responsable (art. 9 del Convenio de La Haya de 1971, que establece, con carácter general, que la acción directa es posible si así la contempla la Ley aplicable conforme al art. 3) ${ }^{29}$. Por otro, la Ley portuguesa, al ser la Ley aplicable a la responsabilidad civil extracontractual, rige todas las cuestiones a las que se refiere el art. 8 del Convenio ${ }^{30}$ (ej. las condiciones y el alcance de la responsabilidad, la existencia y la índole de los daños indemnizables, la prescripción y caducidad por expiración de un plazo, etc.).

\section{Prueba del Derecho extranjero}

22. La última cuestión a la que nos referiremos es la relativa a la prueba del Derecho portugués que, como se ha indicado, es la Ley aplicable al caso.

Como el Convenio de La Haya de 1971 no regula la prueba del Derecho extranjero, dicha cuestión se rige por el Derecho internacional privado de producción interna del tribunal que conoce del asunto ${ }^{31}$.

23. En la Sentencia se indica que el demandante solicitó una indemnización de 12.100 euros, entendiendo que el camión articulado de matrícula portuguesa había vulnerado el art. 38 del Código de Circulación de Portugal y que procedía sumar a la cantidad reclamada los intereses conforme al art. 20 de la Ley de Contrato de Seguro ${ }^{32}$.

24. La Audiencia Provincial, al igual que en primera instancia, plantea que las partes se han remitido al Código de Circulación de Portugal, si bien ésta es una norma de carácter administrativo que no regula la responsabilidad civil ${ }^{33}$. Por dicho motivo, la Audiencia considera acertada la decisión de primera instancia que, entendiendo que no había sido probado el Derecho extranjero, procedió a aplicar Derecho español, en virtud del art. 33.3 de la Ley 29/2015, de 30 de julio, de Cooperación jurídica internacional en materia civil ${ }^{34}$.

25. Nos encontramos, por lo tanto, ante un caso en el que, si bien las partes se remiten al Derecho extranjero que resulta aplicable -Derecho portugués-, no lo hacen a la norma que, en concreto, resulta aplicable en materia de responsabilidad civil, sino a una norma portuguesa de carácter administrativo ${ }^{35}$.

${ }^{28}$ Vid. la comparación que se realiza entre las soluciones del Convenio de La Haya de 1971 y del Reglamento Roma II, en A. Ortega GimÉneZ, "3 x 1 = Competencia judicial internacional, determinación de la Ley aplicable y prueba del derecho extranjero en materia de accidentes de circulación por carretera (A propósito de la Sentencia de la Audiencia Provincial de Barcelona de 19 de junio de 2020)", Diario La Ley, núm. 9724, de 27 octubre 2020, pp. 7-8.

${ }^{29}$ A. L. Calvo Caravaca / J. Carrascosa GonzÁlez, "Obligaciones extracontractuales", en A. L. Calvo Caravaca / J. CARRASCosa GonzÁlez (dirs.), Tratado de Derecho internacional privado, t. III, Valencia, Tirant lo blanch, 2020, p. 1083.

${ }^{30}$ Ídem.

${ }^{31}$ Ibidem, p. 1081.

${ }^{32}$ SAP (Sección 1a) Barcelona 19 junio 2020, Roj: SAP B 5205/2020, ECLI: ES:APB:2020:5205, Fundamento de Derecho Primero, punto I. El art. 38 del Código mencionado se refiere a la realización de maniobras (vid. versión consolidada del Código da Estrada, Lei núm. 72/2013, Diário da República núm. 169/2013, Série I de 3 septiembre 2013, ELI: https://data.dre.pt/eli/ lei/72/2013/p/cons/20200114/pt/html ).

${ }^{33}$ SAP (Sección $1^{\text {a }}$ ) Barcelona 19 junio 2020, Roj: SAP B 5205/2020, ECLI: ES:APB:2020:5205, Fundamento de Derecho Tercero, punto II.

${ }^{34}$ BOE núm. 182, de 31 julio 2015, disponible en https://www.boe.es/eli/es/1/2015/07/30/29/con

${ }^{35}$ No se trata, por lo tanto, de un caso en el que el demandante omite cualquier referencia al Derecho extranjero. Vid. SAP Asturias 10 febrero 2012, JUR $\backslash 2012 \backslash 88962$, Fundamento de Derecho Tercero, relativa a un accidente de circulación ocurrido en Marruecos, caso en el que el demandante se basó únicamente en el Derecho español y la parte demandada alegó que resultaba 
Cabe apuntar que la referencia al Código de Circulación de Portugal no es totalmente carente de sentido, puesto que el art. 7 del Convenio de La Haya de 1971 establece que, para determinar la responsabilidad “...se deberán tener en cuenta las normas sobre circulación y seguridad que estuvieren en vigor en el lugar y momento del accidente" y, como se ha indicado, el accidente tuvo lugar en Portugal.

26. Esta remisión al Código de la Circulación de Portugal y no a la norma en materia de responsabilidad civil también se produjo, por ejemplo, en el caso resuelto por la SAP Madrid 17 enero 2019, relativa a un accidente de circulación que tuvo lugar en Portugal el 3 de febrero de $2015^{36}$. En este caso, el demandante aludió al mencionado Código, pero no acreditó la norma portuguesa que regía la responsabilidad en materia de circulación de vehículos de motor $^{37}$. La Audiencia Provincial de Madrid, citando la STS 17 abril 2015, entendió que se trataba de un caso de falta de prueba del Derecho extranjero y que, por ello, procedía la aplicación del Derecho español ${ }^{38}$.

27. La solución que acoge la SAP Barcelona 19 de junio 2020 provoca también que se aplique el Derecho español a un caso al que la norma de conflicto determina aplicable el Derecho portugués. Así, en la SAP se sigue la "tesis de la aplicación sustitutiva" del Derecho español ${ }^{39}$. Para ello, un supuesto excepcional, como es el contemplado en el art. 33.3 LCJIMC ("Con carácter excepcional, en aquellos supuestos en los que no haya podido acreditarse por las partes el contenido y vigencia del Derecho extranjero, podrá aplicarse el Derecho español"), es empleado en la Sentencia como argumento para justificar la aplicación del Derecho español ${ }^{40}$.

28. Cabría sostener, como apunta parte de la doctrina, que cuando el art. 33.3 LCJIMC se refiere a "aquellos supuestos en los que no haya podido acreditarse por las partes el contenido y vigencia del Derecho extranjero", está haciendo alusión a casos de "imposibilidad fáctica de prueba del Derecho extranjero", imposibilidad que no concurre en el caso analizado ${ }^{41}$. Siguiendo la tesis de este sector doctrinal, al no encontrarse basada la demanda en la norma portuguesa en materia de responsabilidad civil, cabría entender que no ha sido correctamente fundamentada la pretensión y, por ello, en lugar de activar el art. 33.3 LCJIMC, la Audiencia Provincial podría haber desestimado la demanda por este motivo ${ }^{42}$.

\section{Conclusiones}

29. Los perjudicados en un accidente de circulación con elemento extranjero pueden ejercitar una acción directa ante los tribunales del Estado miembro de su domicilio (y, en concreto, del lugar de

aplicable el Derecho marroquí, pero se limitó a invocar al respecto el principio "iura novit curia". Vid. también, sobre la "mera invocación genérica", A. L. Calvo Caravaca / J. Carrascosa González, "Obligaciones extracontractuales", en A. L. Calvo CARavaCa / J. CARrascosa González (dirs.), Tratado de Derecho internacional privado, t. I, Valencia, Tirant lo blanch, 2020 , p. 688.

${ }^{36}$ SAP Madrid (Sección 12a) 17 enero 2019, ECLI: ES:APM:2019:773, Fundamento de Derecho Cuarto: "No obstante, si bien el demandante alude al artículo 30 del Código de Circulación Portugués, no acredita la norma reguladora de la responsabilidad en materia de circulación de vehículos de motor aplicable en dicho país (...). La parte demandada, a este respecto, señala que es aplicable la legislación portuguesa y que dado que la actora cita la legislación española, la demanda debe ser desestimada, si bien señalando, subsidiariamente, que si se entendiese de aplicación la legislación española lo procedente sería desestimar la demanda".

${ }^{37}$ Ibidem, Fundamento de Derecho Cuarto.

${ }^{38}$ Ídem.

${ }^{39}$ Con respecto a las críticas a dicha tesis, vid., entre otros, A. L. Calvo Caravaca / J. Carrascosa González, "Obligaciones extracontractuales", en A. L. Calvo Caravaca / J. CARrascosa GonzÁlez (dirs.), Tratado de Derecho internacional privado, t. I, Valencia, Tirant lo blanch, 2020, pp. 710-711.

${ }^{40}$ Ibidem, p. 710. Vid. STS 3 abril 2018, ECLI: ES:TS:2018:1228, Fundamento de Derecho cuarto, que apunta "la aplicación al caso del derecho español, que según el art. 33.3 de la citada Ley 29/2015 debe hacerse solo con carácter «excepcional», cuando no haya podido acreditarse por las partes el contenido y vigencia del derecho extranjero, resulta incorrecta".

${ }^{41}$ A. L. Calvo Caravaca / J. Carrascosa GonzÁlez, "Obligaciones extracontractuales", en A. L. Calvo Caravaca / J. CaRRASCOSa GonzÁlez (dirs.), Tratado de Derecho internacional privado, t. I, Valencia, Tirant lo blanch, 2020, p. 717.

42 Ídem. 
su domicilio) contra el asegurador domiciliado en otro Estado miembro. Dicho foro se encuentra basado en la remisión que el art. 13.2 del Reglamento 1215/2012 hace al art. 11.1.b), atendiendo a la interpretación que de tal remisión ha hecho el Tribunal de Justicia en el caso Odenbreit.

Por esta vía, el perjudicado logra -siempre que la Ley aplicable permita la acción directa-: a) litigar ante los tribunales del lugar de su domicilio contra el asegurador del responsable; b) evita litigar ante los tribunales del Estado miembro del domicilio del asegurador; y c) no surgirán dudas sobre la falta de legitimación pasiva de los representantes para la tramitación y liquidación de siniestros.

30. Cuando los tribunales competentes son los españoles, la Ley aplicable a la responsabilidad civil extracontractual resultante de los accidentes de circulación por carretera ha de venir determinada por el Convenio de La Haya de 1971. Ello se debe a que, en virtud del art. 28 del Reglamento Roma II, el Convenio prevalece sobre el Reglamento en los Estados miembros que lo han ratificado.

31. Si la Ley aplicable, en virtud del Convenio de La Haya de 1971, es un Derecho extranjero, los perjudicados han de probar tal Derecho ante los tribunales españoles. Si bien resulta pertinente la referencia a normas administrativas de circulación y seguridad del lugar del accidente (puesto que el Convenio de La Haya de 1971 establece que tales normas serán tenidas en cuenta para para determinar la responsabilidad); los perjudicados han tener presente que tales normas no rigen la responsabilidad civil $\mathrm{y}$, por lo tanto, tienen que probar el Derecho que rige esta última.

32. A la vista de la complejidad que rodea a casos como el analizado, cabe concluir, inspirándonos en una conocida película: "mal día para tener un accidente". 